\title{
Spatial and Temporal Analyses of Citrus Sudden Death as a Tool to Generate Hypotheses Concerning Its Etiology
}

\author{
Renato B. Bassanezi, Armando Bergamin Filho, Lilian Amorim, \\ Nelson Gimenes-Fernandes, Tim R. Gottwald, and Joseph M. Bové
}

First and fourth authors: Fundecitrus, Av. Dr. Adhemar P. de Barros, 201, CEP 14807-040, Araraquara, SP, Brazil; second and third authors: Departamento de Entomologia, Fitopatologia e Zoologia Agrícola, Escola Superior de Agricultura Luiz de Queiroz, Universidade de São Paulo, CEP 13418-900, Piracicaba, SP, Brazil; fifth author: U.S. Department of Agriculture-Agricultural Research Service, USHRL, 2001 South Rock Rd., Fort Pierce, FL 34945; and sixth author: Institut Nationale de la Recherche Agronomic, 33883 Villenave d'Ornon, France.

Accepted for publication 9 November 2002.

\begin{abstract}
Bassanezi, R. B., Bergamin Filho, A., Amorim, L., Gimenes-Fernandes, N., Gottwald, T. R., and Bové, J. M. 2003. Spatial and temporal analyses of citrus sudden death as a tool to generate hypotheses concerning its etiology. Phytopathology 93:502-512.

Citrus sudden death (CSD), a new disease of unknown etiology that affects sweet orange grafted on Rangpur lime, was visually monitored for 14 months in 41 groves in Brazil. Ordinary runs analysis of CSD-symptomatic trees indicated a departure from randomness of symptomatic trees status among immediately adjacent trees mainly within rows. The binomial index of dispersion $(D)$ and the intraclass correlation $(k)$ for various quadrat sizes suggested aggregation of CSD-symptomatic trees for almost all plots within the quadrat sizes tested. Estimated parameters of the binary form of Taylor's power law provided an overall measure of aggregation of CSD-symptomatic trees for all quadrat sizes tested. Aggregation in each plot was dependent on disease incidence. Spatial autocorrelation analysis of proximity patterns suggested that aggregation often existed among quadrats of various sizes up to three lag distances; however, significant lag positions discontinuous from main proximity patterns were rare, indicating a lack of spatial association among discrete
\end{abstract}

ABSTRACT foci. Some asymmetry was also detected for some spatial autocorrelation proximity patterns, indicating that within-row versus across-row distributions are not necessarily equivalent. These results were interpreted to mean that the cause of the disease was most likely biotic and its dissemination was common within a local area of influence that extended to approximately six trees in all directions, including adjacent trees. Where asymmetry was indicated, this area of influence was somewhat elliptical. Longer-distance patterns were not detected within the confines of the plot sizes tested. Annual rates of CSD progress based on the Gompertz model ranged from 0.37 to 2.02. Numerous similarities were found between the spatial patterns of CSD and Citrus tristeza virus (CTV) described in the literature, both in the presence of the aphid vector, Toxoptera citricida. CSD differs from CTV in that symptoms occur in sweet orange grafted on Rangpur lime. Based on the symptoms of CSD and on its spatial and temporal patterns, our hypothesis is that CSD may be caused by a similar but undescribed pathogen such as a virus and probably vectored by insects such as aphids by similar spatial processes to those affecting CTV.

Additional keywords: Aphis gossypii, binomial variance, Citrus limonia, C. sinensis, disease spread.
Considerable progress in the analysis of spatial and temporal patterns of epidemics has been made in the last two decades $(5,30,41)$. Spatial pattern in plant pathology may be defined as the arrangement of diseased plants relative to each other (14). Temporal pattern, on the other hand, characterizes the progress of the intensity of the disease in relation to time, usually using mathematical models of growth (15). In agroecosystems, these patterns originate from direct or indirect interactions among pathogen, host, environment, vector (when there is one), and man. The analysis of these patterns may allow inferences about the spatial process that give rise to them, such as the behavior of vectors $(20,32)$ and the influence of wind $(22)$ or rain $(35,36)$ in the dissemination of pathogens.

The use of spatial and temporal patterns of diseased plants to make inferences about the nature of the causal agent is rarely discussed in plant pathology, in contrast to medical literature $(9,34,41)$. Collett $(9)$, referring to the epidemiology of human diseases, considered that "the aim of an epidemiological study is to

Corresponding author: A. Bergamin Filho

E-mail address: abergami@carpa.ciagri.usp.br

Publication no. P-2003-0220-01R

This article is in the public domain and not copyrightable. It may be freely reprinted with customary crediting of the source. The American Phytopathological Society, 2003. investigate the cause, or etiology, of a disease or physiological condition." One reason for the limited use of plant epidemiology to investigate the etiology of plant diseases is the time necessary to obtain validated data for spatial and temporal patterns of diseased plants. Such data may not be available for newly emerging disease until reliable detection methods are developed, which requires knowledge of the pathogen and its etiology. Thus, the argument is circular. Therefore, in such cases we must rely on visual disease symptoms alone, the expression of which in perennial crop systems can be considerably separated in time from the period of infection.

Citrus sudden death (CSD) is a new disease of unknown etiology. To our knowledge, the first report of the disease was published in 2001 (16) based on symptomatic plants identified in Minas Gerais (in the counties of Comendador Gomes, Frutal, and Uberlândia) and São Paulo (in the counties of Altair, Barretos, Colômbia, and Guaraci), Brazil. The first observations of the disease were made in 1999 in 'Westin' sweet orange (Citrus sinensis) grafted on Rangpur lime (C. limonia) in Comendador Gomes. In December 1999, in the same area, similar symptoms were identified in other plantings of sweet oranges (cvs. Hamlin, Natal, Valencia, Pera, and Rubi), all grafted on Rangpur lime. Until present, there are no reports of the disease in 'Cleopatra' $(C$. reticulata $)$ and 'Sunki' (C. sunki) mandarins, 'Swingle' citrumelo (Poncirus trifoliata $\times C$. paradisi), and $P$. trifoliata rootstocks (16). 
The initial symptoms of CSD are characterized by a generalized foliar discoloration. The tree also shows partial defoliation, fewer than normal new shoots, and the absence of internal shoots. These symptoms intensify as the disease develops and culminates with the death of the tree. The fruit produced are usually normal in number, weight, and size and do not abscise from the dead or dying tree. Therefore, bloom, maturation, and harvesting of the fruit occur normally and before the sudden collapse of the diseased tree. Assuming a biotic nature of the malady, infection appears to be separated in time from the death of the plant (or the expression of symptoms in the canopy), which occurs abruptly in a few days. Symptom expression and tree death occur when the need for water absorption for the new shoots and maturing of the fruit is high. Roots of affected trees are characterized by death of a large portion of the root system that progresses from the root tips through roots of increasing size until the main scaffold roots are affected and die. CSD is also characterized by the development of a yellow stain in the phloem of the Rangpur lime rootstock (16).

The time lapse between the first visible symptoms in the canopy and the death of the plant ranges from 1 to more than 12 months depending on the time of year (more rapid in the spring) and cultivar (more rapid in late-maturing cultivars). The number of symptomatic trees increased in the area where the disease was initially found from 500 in 1999 to more than 300,000 in February
2002, greatly alarming the Brazilian citrus industry (N. GimenesFernandes, unpublished data).

The sudden appearance of CSD symptoms and the rapid disease progress have similarities with the quick-decline form of citrus tristeza (2,37), caused by Citrus tristeza virus (CTV). CSD, however, affects sweet orange (cvs. Hamlin, Natal, Valencia, Pera, and Rubi) grafted on Rangpur lime (16). This combination is tolerant to the decline form of citrus tristeza. CTV, on the other hand, affects sweet orange grafted on sour orange $(2,37)$. Thus, for CSD, Rangpur lime plays the same role as sour orange does for the CTV pathosystem. Interestingly, ungrafted sweet orange (normally the scion) and ungrafted Rangpur lime (rootstock) are asymptomatic in areas affected by CSD in the same way that ungrafted sweet orange (scion) and sour orange (rootstock) are asymptomatic when infected by CTV. Of the 180 million sweet oranges grown in Brazil today, approximately $85 \%$ are grafted on Rangpur lime, and thus susceptible to the rapidly emerging CSD.

Methods for quantitative analysis of spatial patterns at a single point in time exist that take advantage of the binary (i.e., presence or absence) data generated by the assessment of the incidence of symptomatic plants. Ordinary runs analysis is a unidirectional test that can be used to assess aggregation within columns or rows in a population matrix of diseased plants (31). The beta-binomial discrete distribution is the most appropriate distribution to examine spatial patterns of disease incidence of binary data for the

TABLE 1. Description of the citrus plots where symptomatic trees were assessed for citrus sudden death (CSD)

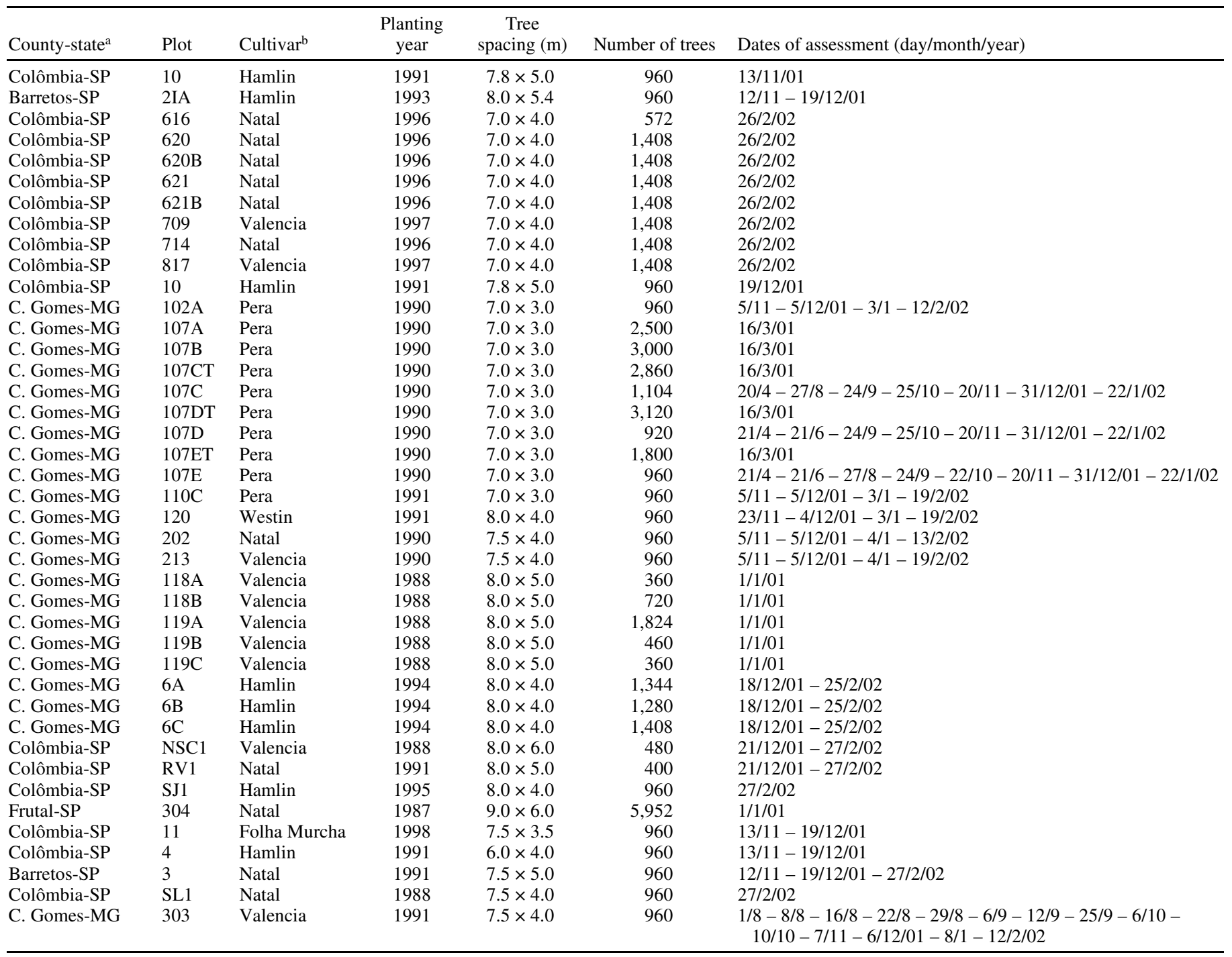

${ }^{\text {a }} \mathrm{SP}=$ State of São Paulo; MG = State of Minas Gerais

${ }^{\mathrm{b}}$ All cultivars were grafted on Rangpur lime. 
presence of randomness within quadrats of different sizes (30). Spatial autocorrelation analysis can be used with binary, as well as continuous, data to analyze the spatial patterns of disease incidence between quadrats (22). Madden and Hughes (30) suggested that for analysis of disease incidence data, the simultaneous study of correlations both within (such as that provided by beta-binomial distribution analysis) and between quadrats (such as provided by spatial autocorrelation analysis) presents interesting new possibilities for epidemic quantification. The combination of these spatial analyses provides a means to examine epidemics at multiple spatial scales and has been applied to another citrus disease (19).

Due to the recent occurrence of the disease, studies on the spatial and temporal dynamics of CSD have not been done previously. In the absence of a known causal agent for CSD, the purpose of this paper was to examine the spatial, temporal, and spatiotemporal dynamics of CSD as a tool to generate hypotheses concerning its etiology. We are aware that a spatial pattern does not necessarily indicate the process from which it originated (40). The basic premise of this study is that the spatial and temporal patterns of diseases of unknown etiology can, after a comparative epidemiological analysis with patterns shown by well-characterized diseases (like citrus tristeza, for example), supply useful indications that might help elucidate its etiology well before the time required for its experimental confirmation (41).

\section{MATERIALS AND METHODS}

Data collection. The spatial pattern of CSD (incidence of symptomatic plants) was visually monitored in 41 citrus plots (i.e., a block within a grove) located in Minas Gerais and São

TABLE 2. Disease incidence, ordinary runs, binomial dispersion index $(D)$, and intraclass correlation $(k)$ analyses of citrus sudden death (CSD) in Brazil based on symptomatic trees

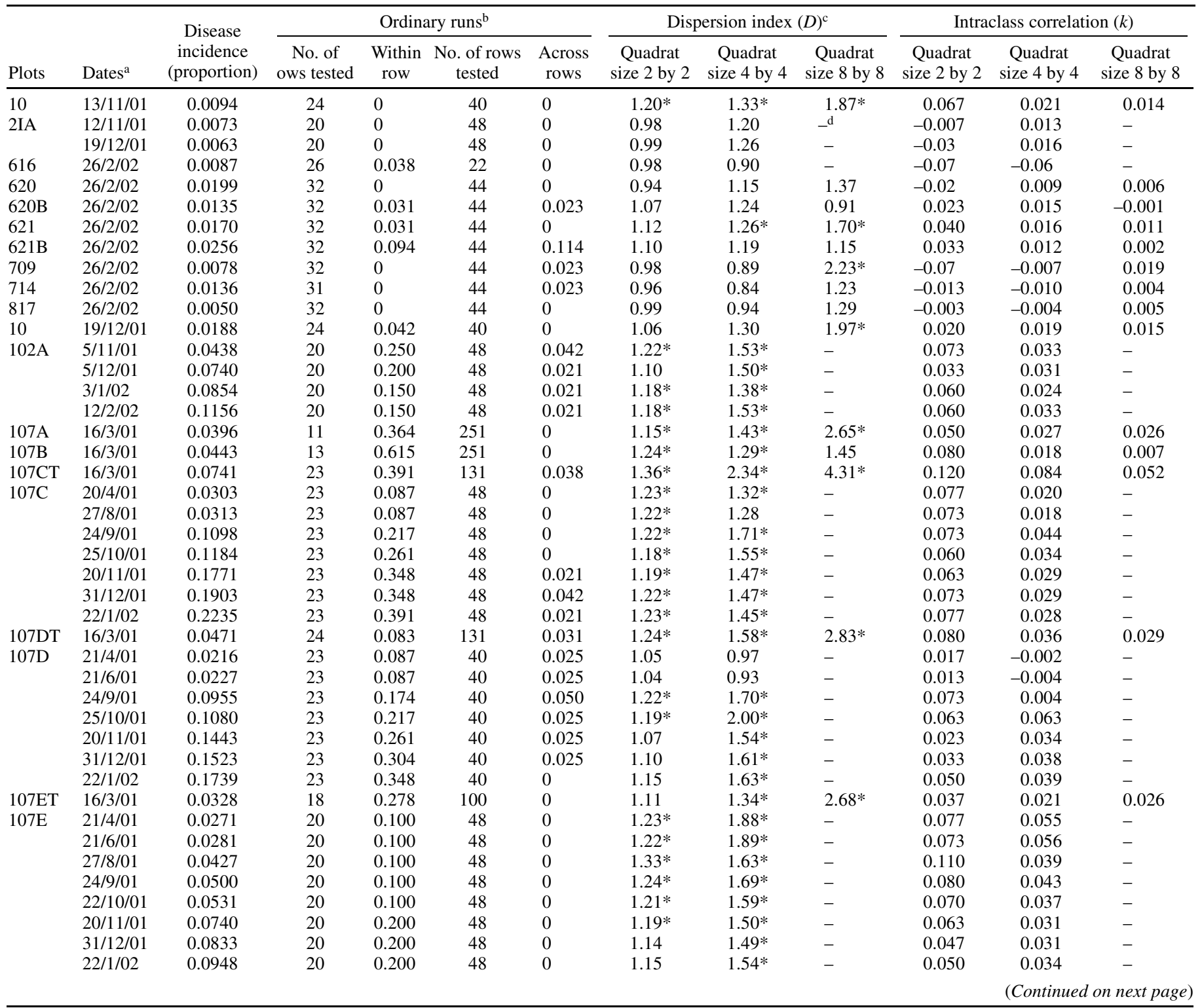

a Day/month/year.

${ }^{b}$ Values shown for each plot in each assessment date are the proportion of the number of test rows with significant aggregation $(P=0.05)$ divided by the total number of rows tested.

${ }^{\mathrm{c}}$ Binomial index of dispersion $(D)$ values for the indicated quadrat size by plot and assessment date for citrus plots in Brazil with CSD symptomatic trees. Values presented for each assessment date are $D$ (=observed variance/binomial variance). Significances $(*)$ were calculated by comparison of df $\times D$ with the chi-square distribution. Values of $D$ not significantly different from $1(0.95>P>0.05)$ indicate that the pattern of symptomatic trees is indistinguishable from random. A large $(>1) D$ and a small $P(\leq 0.05)$ suggest rejection of $H_{0}$ (random pattern) in favor of $H_{1}$ (aggregated pattern of symptomatic trees).

d Too few data points were available to allow calculation. 
Paulo states, Brazil, between January 2001 and February 2002. The number of plants in each plot ranged from 360 to 5,952. Each plot was composed of sweet orange (cvs. Hamlin, Natal, Valencia, Pera, or Westin) grafted on Rangpur lime (Table 1). Incidence of CSD was assessed by visual inspection of the canopies of all trees in each plot. Diagnosistic confirmation of CSD, when necessary, was done through the characteristic yellow stain in the phloem of diseased Rangpur lime rootstock (16). The location of each symptomatic tree and the date when the symptoms appeared were recorded for each of the maps.

The temporal progress of CSD was monitored in nine plots (102A, 107C, 107D, 107E, 110C, 120, 202, 213, and 303) located in the county of Comendador Gomes, Minas Gerais. Visual assessments were made for a minimum of four and a maximum of
14 dates per plot to determine the incidence of symptomatic plants between March 2001 and February 2002. Of the nine monitored plots, five were planted with 'Pera', two with 'Valencia', one with 'Westin', and one with 'Natal'. All were grafted on Rangpur lime (Table 1).

Spatial analysis. Binary (presence/absence) spatial maps of CSD were prepared for all assessment dates for each plot. For the first level of spatial hierarchy, ordinary runs analyses were performed on each data set to determine if aggregation existed between adjacent symptomatic trees within rows and across rows with the use of a Visual Basic EXCEL macro (32; T. R. Gottwald, unpublished data). A nonrandom pattern (i.e., aggregation) of symptomatic trees was assumed if the observed number of runs was less than the expected number of runs at $P=0.05$.

TABLE 2. (Continued from preceding page)

\begin{tabular}{|c|c|c|c|c|c|c|c|c|c|c|c|c|}
\hline \multirow[b]{2}{*}{ Plots } & \multirow[b]{2}{*}{ Dates $^{\mathrm{a}}$} & \multirow{2}{*}{$\begin{array}{c}\text { Disease } \\
\text { incidence } \\
\text { (proportion) }\end{array}$} & \multicolumn{4}{|c|}{ Ordinary runs ${ }^{\mathrm{b}}$} & \multicolumn{3}{|c|}{ Dispersion index $(D)^{\mathrm{c}}$} & \multicolumn{3}{|c|}{ Intraclass correlation $(k)$} \\
\hline & & & $\begin{array}{c}\text { No. of } \\
\text { rows tested }\end{array}$ & $\begin{array}{l}\text { Within } \\
\text { row }\end{array}$ & $\begin{array}{c}\text { No. of } \\
\text { rows tested }\end{array}$ & $\begin{array}{l}\text { Across } \\
\text { rows }\end{array}$ & $\begin{array}{c}\text { Quadrat } \\
\text { size } 2 \text { by } 2\end{array}$ & $\begin{array}{c}\text { Quadrat } \\
\text { size } 4 \text { by } 4\end{array}$ & $\begin{array}{c}\text { Quadrat } \\
\text { size } 8 \text { by } 8\end{array}$ & $\begin{array}{c}\text { Quadrat } \\
\text { size } 2 \text { by } 2\end{array}$ & $\begin{array}{c}\text { Quadrat } \\
\text { size } 4 \text { by } 4\end{array}$ & $\begin{array}{c}\text { Quadrat } \\
\text { size } 8 \text { by } 8\end{array}$ \\
\hline \multirow[t]{4}{*}{$110 \mathrm{C}$} & $5 / 11 / 01$ & 0.1833 & 20 & 0.200 & 48 & 0.042 & $1.35^{*}$ & $2.16^{*}$ & - & 0.117 & 0.073 & - \\
\hline & $5 / 12 / 01$ & 0.2417 & 20 & 0.400 & 48 & 0.021 & $1.29 *$ & $2.07 *$ & - & 0.097 & 0.067 & - \\
\hline & $3 / 1 / 02$ & 0.2708 & 20 & 0.600 & 48 & 0 & $1.35 *$ & $2.11 *$ & - & 0.117 & 0.069 & - \\
\hline & $19 / 2 / 02$ & 0.2906 & 20 & 0.500 & 48 & 0.021 & $1.28 *$ & $1.83^{*}$ & - & 0.093 & 0.052 & - \\
\hline \multirow[t]{4}{*}{120} & $23 / 11 / 01$ & 0.4823 & 20 & 0.400 & 48 & 0.063 & $1.64 *$ & $2.61 *$ & - & 0.213 & 0.101 & - \\
\hline & $4 / 12 / 01$ & 0.6469 & 20 & 0.350 & 48 & 0.167 & $1.84 *$ & $4.31 *$ & - & 0.280 & 0.207 & - \\
\hline & $3 / 1 / 02$ & 0.6604 & 20 & 0.250 & 48 & 0.167 & $1.81 *$ & $4.41 *$ & - & 0.270 & 0.213 & - \\
\hline & $19 / 2 / 02$ & 0.6958 & 20 & 0.200 & 48 & 0.146 & $1.83^{*}$ & $4.32 *$ & - & 0.277 & 0.208 & - \\
\hline \multirow[t]{4}{*}{202} & $5 / 11 / 01$ & 0.1500 & 20 & 0.050 & 48 & 0.021 & $1.24 *$ & $1.80^{*}$ & - & 0.080 & 0.050 & - \\
\hline & $5 / 12 / 01$ & 0.1729 & 20 & 0.100 & 48 & 0 & $1.31 *$ & $1.77 *$ & - & 0.103 & 0.048 & - \\
\hline & 4/1/02 & 0.2188 & 20 & 0.150 & 48 & 0.021 & $1.37 *$ & $1.90^{*}$ & - & 0.123 & 0.056 & - \\
\hline & $13 / 2 / 02$ & 0.2385 & 20 & 0.200 & 48 & 0.042 & $1.42 *$ & $2.16^{*}$ & - & 0.140 & 0.073 & - \\
\hline \multirow[t]{4}{*}{213} & $5 / 11 / 01$ & 0.1771 & 20 & 0.050 & 48 & 0.021 & 1.15 & $1.54 *$ & - & 0.050 & 0.034 & - \\
\hline & $5 / 12 / 01$ & 0.2198 & 20 & 0.300 & 48 & 0 & $1.24 *$ & $1.59 *$ & - & 0.080 & 0.037 & - \\
\hline & $4 / 1 / 02$ & 0.2417 & 20 & 0.150 & 48 & 0 & 1.13 & $1.60 *$ & - & 0.043 & 0.038 & - \\
\hline & $19 / 2 / 02$ & 0.2531 & 20 & 0.100 & 48 & 0.021 & 1.08 & $1.45^{*}$ & - & 0.027 & 0.028 & - \\
\hline $118 \mathrm{~A}$ & 1/1/01 & 0.2944 & 12 & 0 & 30 & 0.033 & 0.96 & 1.10 & - & -0.013 & 0.006 & - \\
\hline $118 \mathrm{~B}$ & $1 / 1 / 01$ & 0.3458 & 20 & 0.100 & 36 & 0.056 & 1.03 & $1.82 *$ & - & 0.010 & 0.051 & - \\
\hline $119 \mathrm{~A}$ & $1 / 1 / 01$ & 0.8640 & 16 & 0.875 & 114 & 0 & $1.29 *$ & $2.57 *$ & $6.70^{*}$ & 0.097 & 0.098 & 0.089 \\
\hline 119B & $1 / 1 / 01$ & 0.8609 & 10 & 0.500 & 46 & 0 & 1.18 & 0.80 & - & 0.060 & -0.013 & - \\
\hline $119 \mathrm{C}$ & 1/1/01 & 0.5611 & 18 & 0.167 & 20 & 0.050 & $1.31 *$ & $2.00 *$ & - & 0.103 & 0.063 & - \\
\hline \multirow[t]{2}{*}{$6 \mathrm{~A}$} & $18 / 12 / 01$ & 0.0461 & 32 & 0.156 & 42 & 0.167 & $1.16^{*}$ & 1.14 & 1.44 & 0.053 & 0.009 & 0.007 \\
\hline & $25 / 2 / 02$ & 0.0499 & 32 & 0.188 & 42 & 0.143 & $1.19 *$ & 1.18 & 1.44 & 0.063 & 0.011 & 0.007 \\
\hline \multirow[t]{2}{*}{$6 \mathrm{~B}$} & $18 / 12 / 01$ & 0.0602 & 32 & 0.125 & 40 & 0.075 & $1.17 *$ & $1.33^{*}$ & 1.11 & 0.057 & 0.021 & 0.002 \\
\hline & $25 / 2 / 02$ & 0.0711 & 32 & 0.156 & 40 & 0.025 & $1.22 *$ & $1.43^{*}$ & $1.66 *$ & 0.073 & 0.027 & 0.010 \\
\hline \multirow[t]{2}{*}{$6 \mathrm{C}$} & $18 / 12 / 01$ & 0.3423 & 32 & 0.031 & 44 & 0.250 & $1.75^{*}$ & $4.34 *$ & $13.78 *$ & 0.250 & 0.209 & 0.200 \\
\hline & $25 / 2 / 02$ & 0.3849 & 32 & 0.063 & 44 & 0.295 & $1.78 *$ & $4.84^{*}$ & $14.8^{*}$ & 0.260 & 0.240 & 0.216 \\
\hline \multirow[t]{2}{*}{ NSC1 } & $21 / 12 / 01$ & 0.0063 & 24 & 0 & 20 & 0 & 0.99 & 0.94 & - & -0.003 & -0.004 & - \\
\hline & $27 / 2 / 02$ & 0.0083 & 24 & 0 & 20 & 0 & 0.98 & 0.90 & & -0.07 & -0.006 & \\
\hline RV1 & $21 / 12 / 01$ & 0.0300 & 10 & 0.100 & 40 & 0.025 & $1.78 *$ & $2.08 *$ & - & 0.260 & 0.068 & - \\
\hline & $27 / 2 / 02$ & 0.0325 & 10 & 0.100 & 40 & 0.025 & $1.71 *$ & $2.07 *$ & & 0.237 & 0.067 & \\
\hline SJ1 & $27 / 2 / 02$ & 0.0031 & 24 & 0 & 40 & 0 & 0.99 & 0.97 & 0.86 & -0.03 & -0.002 & -0.002 \\
\hline 304 & 1/1/01 & 0.1452 & 49 & 0.531 & 124 & 0.202 & $1.81 *$ & $3.21 *$ & $9.00 *$ & 0.270 & 0.138 & 0.125 \\
\hline 11 & $13 / 11 / 01$ & 0.0045 & 23 & 0 & 40 & 0 & 0.99 & 0.94 & - & -0.03 & -0.004 & - \\
\hline & $19 / 12 / 01$ & 0.0031 & 24 & 0 & 40 & 0 & 0.99 & 0.97 & & -0.03 & -0.002 & \\
\hline 4 & $13 / 11 / 01$ & 0.0063 & 24 & 0.042 & 40 & 0 & $1.32 *$ & 1.26 & 1.37 & 0.107 & 0.016 & 0.006 \\
\hline & $19 / 12 / 01$ & 0.0094 & 24 & 0.042 & 40 & 0 & $1.20 *$ & 1.10 & 0.91 & 0.067 & 0.006 & -0.001 \\
\hline 3 & $12 / 11 / 01$ & 0.0031 & 20 & 0 & 48 & 0 & 0.99 & 0.97 & - & -0.003 & -0.002 & - \\
\hline & $19 / 12 / 01$ & 0.0042 & 20 & 0 & 48 & 0 & 0.99 & 0.95 & - & -0.03 & -0.003 & - \\
\hline & $27 / 2 / 02$ & 0.0063 & 20 & 0 & 48 & 0 & 0.98 & 0.92 & - & -0.07 & -0.005 & - \\
\hline SL1 & $27 / 2 / 02$ & 0.0219 & 24 & 0.042 & 40 & 0.050 & $1.23 *$ & $1.86^{*}$ & $3.63 *$ & 0.077 & 0.054 & 0.041 \\
\hline 303 & $1 / 8 / 01$ & 0.0250 & 20 & 0 & 48 & 0 & $1.27 *$ & $1.67 *$ & - & 0.090 & 0.042 & - \\
\hline & 8/8/01 & 0.0292 & 20 & 0 & 48 & 0 & $1.21 *$ & $1.46^{*}$ & - & 0.070 & 0.029 & - \\
\hline & 16/8/01 & 0.0760 & 20 & 0.050 & 48 & 0.042 & 1.08 & $1.60 *$ & - & 0.027 & 0.038 & - \\
\hline & $22 / 8 / 01$ & 0.0938 & 20 & 0.150 & 48 & 0.021 & $1.28 *$ & $1.73^{*}$ & - & 0.093 & 0.046 & - \\
\hline & 29/8/01 & 0.1031 & 20 & 0.150 & 48 & 0.021 & $1.25^{*}$ & $1.60 *$ & - & 0.083 & 0.038 & - \\
\hline & $6 / 9 / 01$ & 0.1583 & 20 & 0.050 & 48 & 0.042 & $1.38 *$ & $1.76^{*}$ & - & 0.127 & 0.048 & - \\
\hline & $12 / 9 / 01$ & 0.2490 & 20 & 0.250 & 48 & 0.063 & $1.35^{*}$ & $1.60 *$ & - & 0.117 & 0.038 & - \\
\hline & $25 / 9 / 01$ & 0.2531 & 20 & 0.200 & 48 & 0.063 & $1.31 *$ & $1.54 *$ & - & 0.103 & 0.034 & - \\
\hline & $6 / 10 / 01$ & 0.3125 & 20 & 0.350 & 48 & 0.042 & $1.19^{*}$ & $1.78^{*}$ & - & 0.063 & 0.049 & - \\
\hline & $10 / 10 / 01$ & 0.3323 & 20 & 0.300 & 48 & 0.042 & $1.19 *$ & $1.86^{*}$ & - & 0.063 & 0.054 & - \\
\hline & $7 / 11 / 01$ & 0.4854 & 20 & 0.100 & 48 & 0.021 & $1.20 *$ & $1.96^{*}$ & - & 0.067 & 0.060 & - \\
\hline & $6 / 12 / 01$ & 0.5438 & 20 & 0.150 & 48 & 0.063 & $1.34 *$ & $2.03 *$ & - & 0.113 & 0.064 & - \\
\hline & $8 / 1 / 02$ & 0.6010 & 20 & 0.250 & 48 & 0.042 & $1.42 *$ & $2.39 *$ & - & 0.140 & 0.087 & - \\
\hline & $12 / 2 / 02$ & 0.6135 & 20 & 0.250 & 48 & 0.042 & $1.44^{*}$ & $2.34^{*}$ & - & 0.147 & 0.084 & - \\
\hline
\end{tabular}


For the second level of spatial hierarchy, the data were examined for the presence of aggregation at various quadrat sizes. The incidence data for each plot were partitioned into quadrats of 4 ( 2 by 2 ), 16 ( 4 by 4 ), and 64 ( 8 by 8 ) trees with the use of a Visual Basic EXCEL macro (T. R. Gottwald, unpublished data). When data are expressed as disease incidence, the beta-binomial distribution provides the best adjustment for random conditions (30). Randomness within quadrat was thus assessed via beta-binomial analysis. The beta-binomial index of dispersion $(D)$ was used to test for the presence of randomness of CSD-symptomatic trees at each quadrat size (30). For the beta-binomial index, a large index of dispersion $(D>1)$ combined with a small probability $(P<0.05)$ suggests aggregation of symptomatic trees $(30)$. The intraclass correlation $(k)$, which measures the tendency of the plants within a sampling quadrat to have a similar disease status, was also used to test for the presence of randomness of CSD-symptomatic trees at each quadrat size. Positive values of $k$ indicate aggregation of disease; $k$ is related to the index of dispersion $(D)$ by $k=(D-1) /(n-1)$, where $n$ is the quadrat size (42).

The binary form of Taylor's power law (26) relates the observed variance $\left(v_{\mathrm{obs}}\right)$ and the expected binomial variance $\left(v_{\text {bin }}\right)$ for a random distribution of binary data. In this case, $\log \left(v_{\text {obs }}\right)=\log (A)$ $+b \log \left(v_{\text {bin }}\right)$, where $A$ and $b$ are parameters. Linear regression was performed for all plots using the least squares method, and the significance of the relationship between $\log \left(v_{\mathrm{obs}}\right)$ and $\log \left(v_{\mathrm{bin}}\right)$ was determined by the $F$ test, and the appropriateness of the model was evaluated by the coefficient of determination $\left(R^{2}\right)$ and by the pattern of the residuals of regression. A random condition in the spatial distribution of symptomatic plants is inferred when $b=A=$ 1 . There is a constant level of aggregation for all of the incidence values when $b=1$ and $A>1$. When $b>1$, the degree of aggre-
A
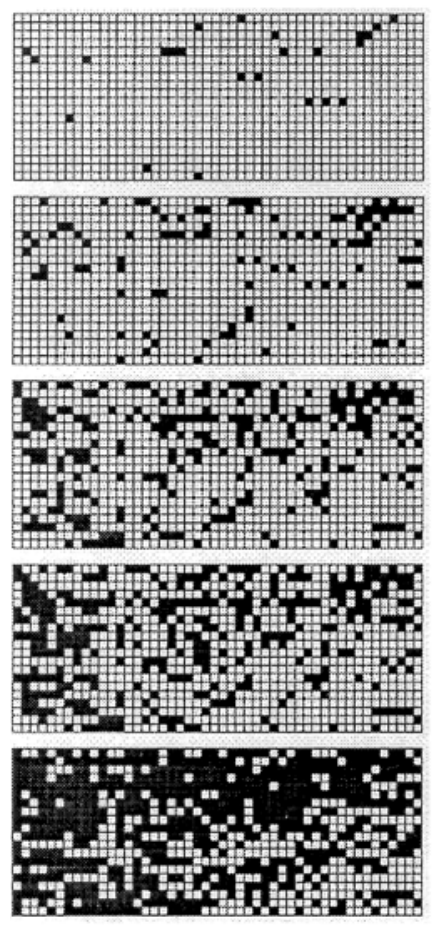

B

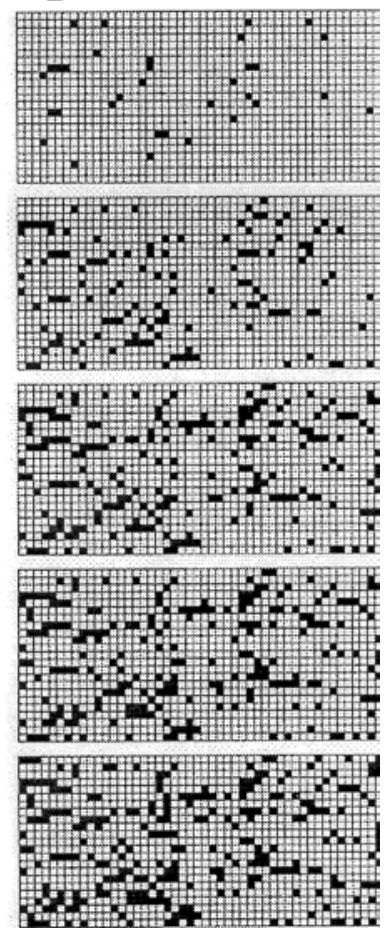

Fig. 1. Spatial patterns of citrus sudden death over time. Black squares are symptomatic trees and white squares, asymptomatic trees. A, Plot 303; dates (and incidence) from top to bottom are 1 August (0.02), 29 August (0.10), 25 September (0.25), 7 November (0.48) 2001, and 22 February (0.61) 2002; within (horizontal lines) and across-row (vertical lines) spacings are $7.5 \times$ $4.0 \mathrm{~m}$. B, Plot $107 \mathrm{C}$; dates (and incidence) from top to bottom are 20 April (0.03), 24 September (0.11), 20 November (0.18), 31 December (0.19) 2001, and 22 January (0.22) 2002; within (horizontal lines) and across-row (vertical lines) spacings are $7.0 \times 3.0 \mathrm{~m}$. gation varies according to the incidence. The equality of parameters $b$ and $A$ to unity was tested by the $t$ test, using the estimate of the parameter and its standard deviation (6).

In the third level of spatial hierarchy, the strength and directionality or orientation of aggregation among quadrats of various sizes containing symptomatic citrus trees for plots 107C, 107D, 107E, 110C, 120, 202, 213, and 303 were examined with spatial autocorrelation analysis (23). The $x, y$ spatial location and disease incidence of trees for each quadrat size on each assessment date in the individual citrus plots were used as input data. Autocorrelation proximity patterns were calculated consisting of positively (SL+), negatively (SL-), and noncorrelated lag positions from which an evaluation of spatial patterns of disease incidence was performed. The size and shape of core and reflected clusters of SL+ were calculated, in which a core cluster is a group of significant, positively correlated $(P=0.05)$, spatial lag distance classes that form a discrete and contiguous group with the origin (i.e., lag [0.0]) of the autocorrelation proximity pattern; a reflected cluster is a discrete group of two or more contiguous significant positive lag positions discontiguous with the origin and the core cluster. The strength of aggregation is a measure of the saturation of the
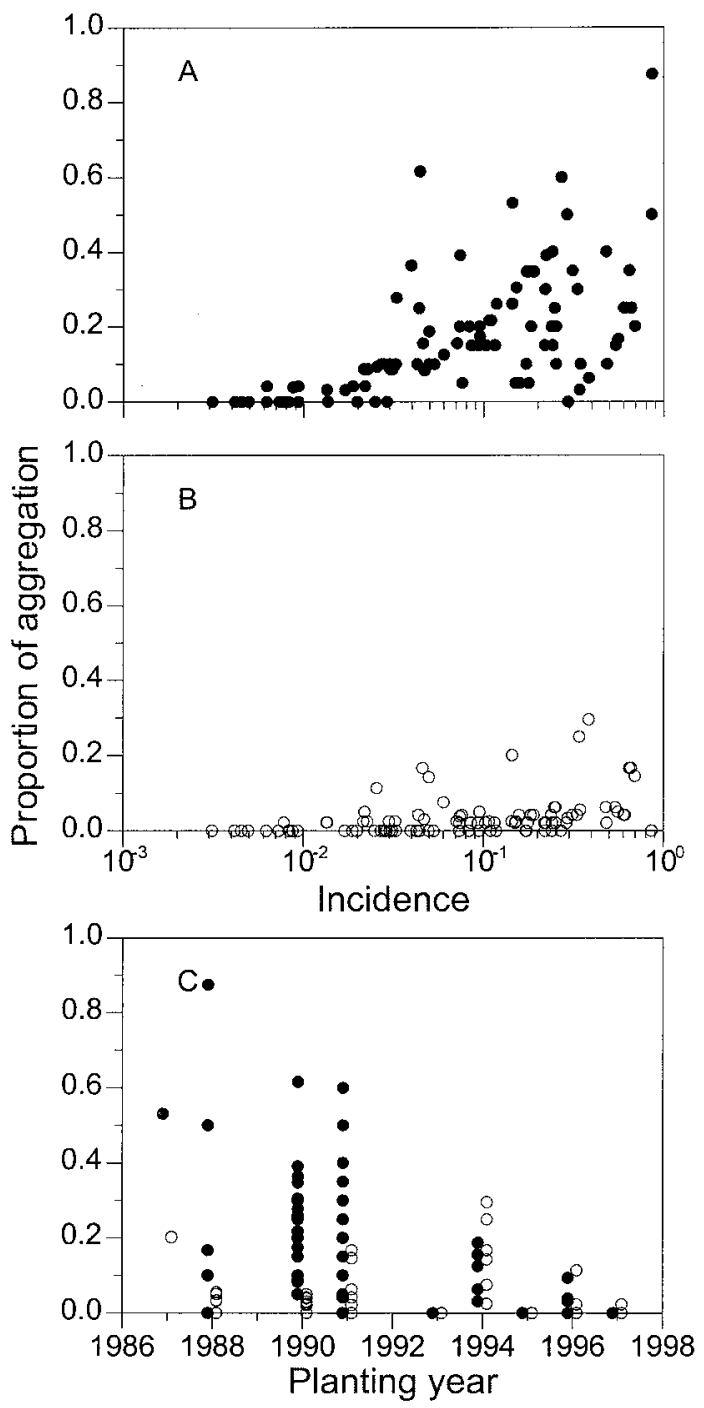

Fig. 2. Ordinary runs analysis of citrus sudden death in Brazil based on disease incidence of symptomatic trees. Aggregation for each plot in each incidence or planting year is the proportion of the number of test rows with significant aggregation $(P=0.05)$ divided by the total number of rows tested. A, Aggregation and incidence within row; $\mathbf{B}$, aggregation and incidence across row; and $\mathbf{C}$, aggregation and planting year within row (closed circle) and across row (open circle). 
core clusters with significantly positive lags (i.e., the proportion of lag positions within the extents of the cluster that were significantly positive). Row effects were evaluated as the number of significant lag positions within the first row (within) or within the first column (across) of the autocorrelation proximity pattern that are contiguous with the origin $(6,19,40)$.

Temporal analysis. The incidence of CSD (number of symptomatic plants divided by the total number of plants) for each evaluation date in each plot having multiple assessment dates (102A, 107C, 107D, 107E, 110C, 120, 202, 213, and 303) was plotted against time. Daily records of rainfall were collected from locations in close proximity to the evaluated plots. An estimate of the rate of disease increase during the study period with the Gompertz model was obtained using the first and the last value of incidence for five of the nine plots (102A, 107C, 107D, 107E, and 303). The rates calculated in this way for CSD are directly comparable with annual rates (between first and second year) of other diseases (like citrus tristeza) published in the literature.
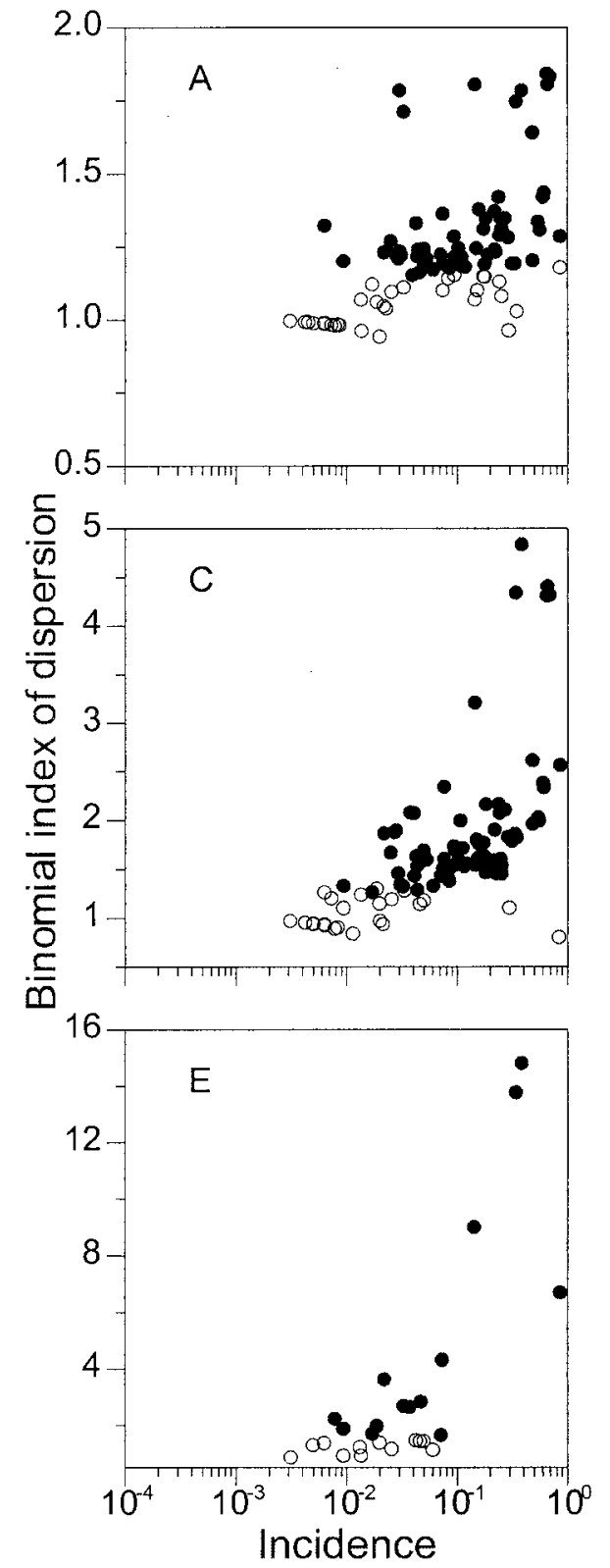

\section{RESULTS}

Spatial arrangement of CSD-symptomatic trees. The first level of spatial hierarchy examined was the association of symptom status between adjacent trees (Table 2). Overall, for the 98 maps examined (Fig. 1, maps of plots 303 and 107C, as example), aggregation within rows was detected in $81.6 \%$ of the maps (Table 2; Fig. 2A) and aggregation across rows was detected in $57.1 \%$ of the maps (Table 2; Fig. 2B). From the 2,176 rows tested, 349 were aggregated $(16.0 \%)$. From the 5,128 across rows tested, only 167 were aggregated (3.2\%) (Table 2). Aggregation between symptomatic adjacent plants increased with the increase in CSD incidence (Fig. 2A and B), especially in older plots (Fig. 2C).

The next level of spatial hierarchy examined was the association of symptomatic plants within quadrats of various sizes. The interpretation of the values of the beta-binomial index of dispersion $(D)$ suggests a spatial structure of symptomatic plants significantly nonrandom (i.e., aggregated) for the majority of the plots and quadrat sizes tested (Table 2), especially between incidence
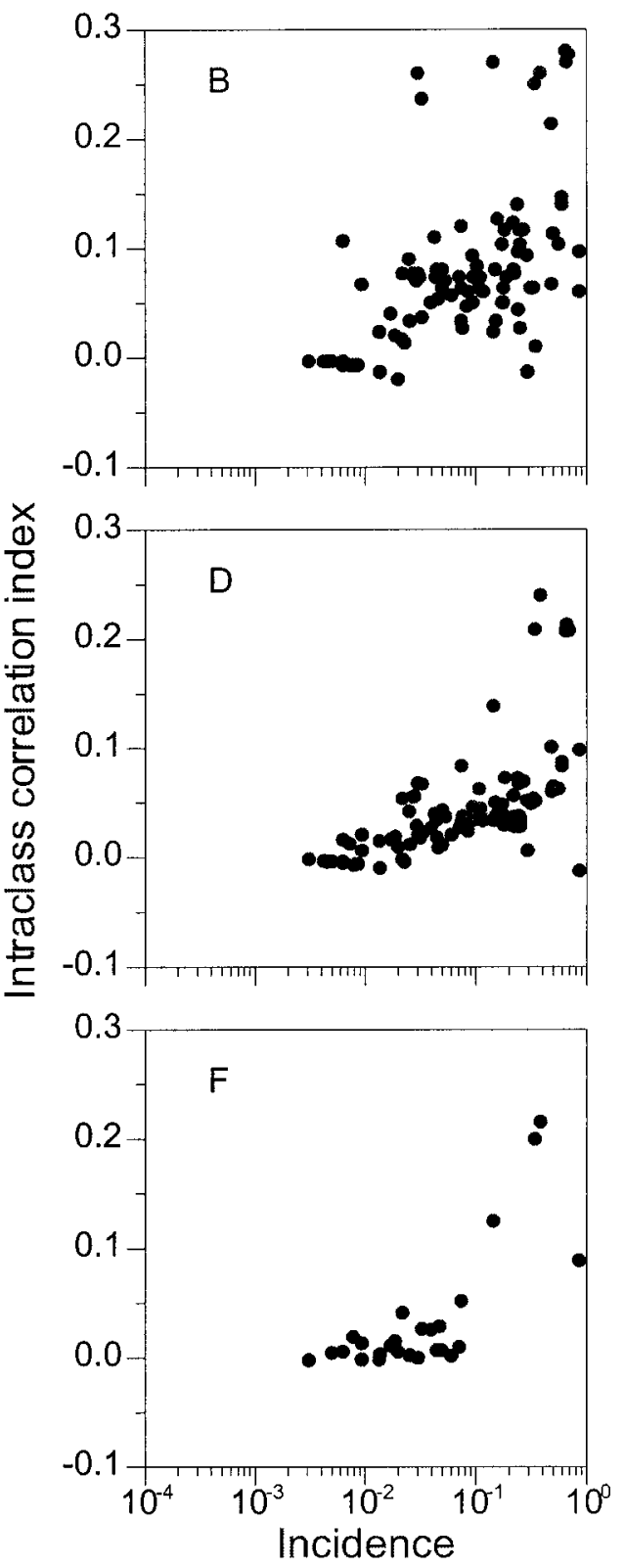

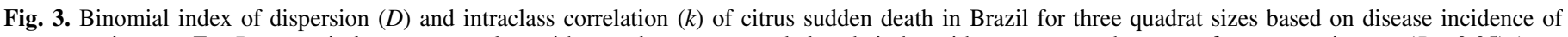

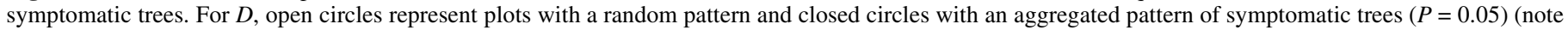
different $y$ axis scales). For $k$, positive values indicate aggregation of symptomatic trees. Quadrat sizes are $\mathbf{A}$ and $\mathbf{B}, 2$ by $2, \mathbf{C}$ and $\mathbf{D}, 4$ by 4, and $\mathbf{E}$ and $\mathbf{F}, 8$ by 8 . 
values of $>0.01$ and $<0.9$, independently of the size of the quadrat (Fig. 3). $D$ values were usually higher for the largest quadrat sizes, with averages of $1.23,1.69$, and 3.24 for 2 by 2,4 by 4 , and 8 by 8 quadrat sizes, respectively. The interpretation of the values of the intraclass correlation $(k)$ also suggests a spatial structure of symptomatic plants significantly nonrandom for the majority of the plots and quadrat sizes tested (Table 2), especially for higher incidence values, independent of the quadrat size (Fig. 3). $k$ values became smaller as quadrat sizes increased, indicating less interclass correlation (saturation) at higher quadrat sizes (Table 2; Fig. 3 ).

The relationship between $\log \left(v_{\text {obs }}\right)$ and $\log \left(v_{\text {bin }}\right)$ was highly significant $(P<0.001)$ for the three sizes of quadrat (Fig. 4). Estimates of $b$ and $A$ were, respectively, $1.07(\mathrm{SE}=0.01)$ and 0.22
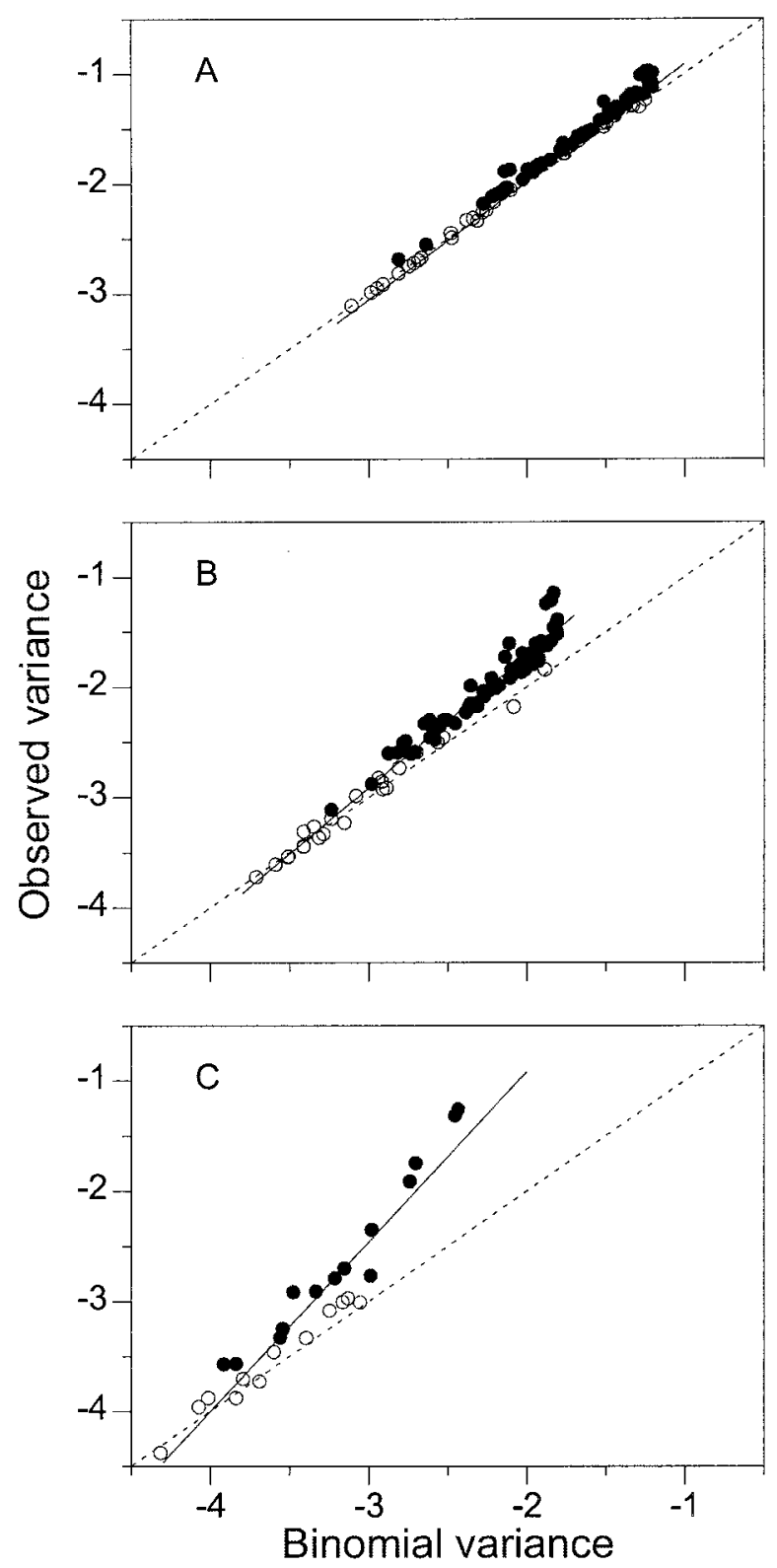

Fig. 4. The relationship between the observed and the theoretical binomial (random) variance of incidence of citrus sudden death (CSD) (note the use of logarithmic scales on both axes). Each data point represents a CSD assessment (symptomatic trees) in a plot in Brazil. The solid lines represent the relationship $\log \left(v_{\mathrm{obs}}\right)=\log (A)+b \log \left(v_{\text {bin }}\right)$ fitted to the data by ordinary least squares regression. The dashed lines represent the binomial line (i.e., observed variance $=$ binomial variance). $\mathbf{A}$, Quadrat size 2 by $2: b=1.07$ $(\mathrm{SE}=0.01), A=0.22(\mathrm{SE}=0.02), R^{2}=0.99 ; \mathbf{B}$, quadrat size 4 by $4: b=1.20$ (0.02), $A=0.69(0.05), R^{2}=0.97 ; \mathbf{C}$, quadrat size 8 by $8: b=1.54(0.09)$, $A=2.17$ (0.32), $R^{2}=0.92$.
(SE $=0.02)$ for the 2 by 2 quadrat $\left(R^{2}=0.99\right) ; 1.20(0.02)$ and $0.69(0.05)$ for the 4 by 4 quadrat $\left(R^{2}=0.97\right)$; and $1.54(0.09)$ and $2.17(0.32)$ for the 8 by 8 quadrat $\left(R^{2}=0.92\right)$. All estimates of $b$ and $A$ were statistically different from $1(P<0.05)$, which indicated a general and significant pattern of aggregation of symptomatic plants within all quadrat sizes tested. Values of $b$ higher than 1 also indicated that the degree of aggregation was a function of incidence. These results support those obtained with the betabinomial index of dispersion, i.e., plants with CSD symptoms show aggregation at relatively low incidence, and aggregation intensifies with time as a consequence of increase of CSD incidence.

The final level of spatial hierarchy examined was the association among groups (quadrats) of trees as estimated by spatial autocorrelation. Spatial autocorrelation analyses results indicated that core clusters existed for quadrat sizes 2 by 2 and 4 by 4 for most plots examined (Table 3); analyses for quadrat size 8 by 8 could not be performed because the majority of plots were too small. The number of significant spatial lags in the core clusters tended to increase as CSD incidence increased, i.e., larger core clusters tended to occur later in the epidemic. When core clusters existed, they tended to exist for both quadrat sizes tested for specific assessment dates. As expected, quadrat size 2 by 2 more often corresponded to the largest core cluster sizes.

In the majority of cases, core clusters were complete (i.e., saturated with significant positive lags) (Table 3). However, in those cases in which core clusters were not completely saturated, strength of aggregation varied from 0.57 to 0.87 and was often associated with an asymmetry of the core cluster. No trends in strength of aggregation of the core clusters were noted over time for any quadrat size by plot combination.

Row effects were detected by spatial lag autocorrelation for most plots (Table 3). Although both within- and across-row effects were detected, when within-row effects existed, they were often stronger. Additionally, within-row effects were more frequently detected (100\% of cases for 2 by 2 and $62.5 \%$ for 4 by 4 quadrat sizes) than across-row effects (50\% of cases for 2 by 2 and $37.5 \%$ for 4 by 4 quadrat sizes). When row effects were detected in both 2 by 2 and 4 by 4 quadrat sizes for a given assessment, row effects were often stronger for 2 by 2 quadrat size. Reflected clusters were very rare for all proximity patterns tested and transient with respect to time. Significant edge effects were detected in 3 of 16 plots for both quadrat sizes (Table 3).

CSD temporal progress. From the nine plots assessed (Fig. 5), five showed low disease incidence $(<0.05)$ in August 2001 (plots 102A, 107C, 107D, 107E, and 303). The other plots were assessed either in October or November. An association between the start of the increase of disease incidence and the beginning of the rainy season was found in the five plots with low incidence of disease in August 2001 (Fig. 5). The beginning of the rainy season in this region corresponds with the period when citrus trees produce the maximal flush of tissues.

The estimated rates of disease increase during the study period, predicted by the Gompertz model were 0.37 (102A, 'Pera'), 0.85 (107C, 'Pera'), 0.78 (107D, 'Pera'), 1.43 (107E, 'Pera'), and 2.02 (303, 'Valencia').

\section{DISCUSSION}

The main goals of this study were to examine the spatiotemporal relationships of CSD-symptomatic trees, including the relationship of newly symptomatic to previous symptomatic trees; to examine the size, shape, and change of spatial patterns of symptomatic trees; and to use this information to make inferences about the etiology of the disease.

For the majority of plots and assessment dates, aggregation among symptomatic trees was detected by ordinary runs analysis. These findings indicate that symptomatic trees influence the status of immediately adjacent trees, the influence being more pro- 
nounced at higher incidences and within rows. This influence was also more common for older plantings within rows. These results are compatible with a biotic causation of CSD, for example, a vector-borne pathogen. The higher aggregation of trees within rows, especially in plots where canopies are in contact, reinforces this hypothesis. Gottwald et al. (21) described a higher aggregation of trees affected with CTV when tree growth eventually leads to a closure of the canopy, presumably due to nonalate aphids crawling from tree to tree within rows.

The next level of spatial hierarchy examined was the association of symptomatic trees within quadrats of various sizes. Interpretation of both the beta-binomial index of dispersion, $D$, and the intraclass correlation, $k$, values suggested a significant nonrandom spatial structure (i.e., aggregation) of symptomatic trees occurred for most plots and quadrat sizes over time when the disease incidence was $>0.01$ and $<0.9$. For all plots on single assessment dates for which aggregation was indicated at more than one quadrat size, significant $D$ values were greater and $k$ values were smaller for larger quadrat sizes. For the latter case, this may mean that the 2 by 2 quadrat size is the most representative of the average focus size.

Estimated parameters of the binary form of Taylor's power law suggested an overall aggregation of CSD-symptomatic trees, with $b>1$ for all quadrat sizes examined. Because $b$ for all quadrat sizes was significantly larger than 1, aggregation at individual times in each plot was predicted to depend on disease incidence $(27,42)$. Also in this case, the values of parameters $b$ and $A$ increased with quadrat size. The positive relationship between aggregation and incidence of symptomatic trees is consistent with the hypothesized behavior of a vector, that is, at low incidences $(<0.01)$, spatial patterns typically were judged to be random, which is consistent with viruliferous vector activity originating from sources external to the plot (21). The trend toward greater and more significant aggregation at higher incidences would then be the result of a predominance of movement of vectors within plots, but mostly among neighboring plants within or across rows, as found in other pathosystems involving a prokaryote or virus pathogen transmitted by a vector $(17,19,21,32)$. Xu and Ridout (42) point out from simulation studies that aggregation increased as disease incidence ( $p$ ) approached 0.5 and decreased when $p$ approached 0 or 1 , for all quadrat sizes tested. In the present study, there were only very few assessments for which $p>0.5$, thus we only recognized this trend as an increase as $p$ increased.

The final spatial scale investigated was the association among quadrats of similar CSD status as determined by spatial autocorrelation, i.e., to examine longer-distance spatial relationships. The existence of core clusters was indicative of a relationship of CSD status among immediately adjacent quadrats. The strength of aggregation values at or near 1.0 for many dates and quadrat sizes when core clusters existed can be interpreted as a strong general association among quadrats within a given area of influence. For the 2 by 2 quadrat size, this relationship often extended to one to three lag positions within row, across row, and at a diagonal. For the 4 by 4 quadrat size, for the same plots and assessment dates, this relationship also existed but was less extensive, as expected, and indicated approximately the same area of influence of similar CSD status. Thus, the area of influence of like-CSD status had a radius of two to six tree spacings. This area of influence can be thought of as the area for local CSD spread. In most of the cases, the core cluster was more extensive within rows than across rows, indicating that an elliptical rather than a circular area of influence existed. The within row predominance was consistent with an interlocking canopy among adjacent trees within rows, as described previously for CTV (21).

The general lack of reflected clusters of significant positive lags indicated that relationships among lags discontinuous from the core cluster were rare. Thus, longer-distance discontinuous relationships among quadrats of similar status were not prevalent. However, had larger plot sizes been used, it is possible that longer-distance relationships may have been detected. Such relationships need to be investigated in the future, but will be costly in time and resources and are beyond the scope of this study.

In the five plots $(102 \mathrm{~A}, 107 \mathrm{C}, 107 \mathrm{D}, 107 \mathrm{E}$, and 303) with low disease incidence $(<0.05)$ in August 2001, the beginning of the disease progress curves was associated with the beginning of the rainy season and coincided with the period of highest flushing of the citrus trees. In CSD, the disease process may have started many months prior to the symptoms expression. In field condi-

TABLE 3. Spatial autocorrelation analysis for citrus sudden death (CSD) in citrus orchards in Brazil (quadrat sizes 2 by 2 and 4 by 4 )

\begin{tabular}{|c|c|c|c|c|c|c|c|c|c|c|c|}
\hline \multirow[b]{2}{*}{ Plot } & \multirow[b]{2}{*}{ Date } & \multirow{2}{*}{$\begin{array}{c}\text { Disease } \\
\text { incidence }^{\mathrm{a}}\end{array}$} & \multicolumn{2}{|c|}{ No. significant ${ }^{\mathrm{b}}$} & \multirow{2}{*}{$\begin{array}{c}\text { Strength } \\
\text { aggregation }^{c}\end{array}$} & \multirow{2}{*}{$\begin{array}{l}\text { Core cluster } \\
\text { size }^{\mathrm{d}}\end{array}$} & \multirow{2}{*}{$\begin{array}{l}\text { No. of reflected } \\
\text { cluster }^{\mathrm{e}}\end{array}$} & \multirow{2}{*}{$\begin{array}{l}\text { Total no. of } \\
\text { clusters }^{\mathrm{f}}\end{array}$} & \multicolumn{3}{|c|}{ Effects ${ }^{\mathrm{g}}$} \\
\hline & & & SL+ & SL- & & & & & Within row & Across row & Edge \\
\hline \multicolumn{12}{|l|}{$2 \times 2$} \\
\hline $107 \mathrm{C}$ & $22 / 01 / 02$ & 0.2235 & 1 & 0 & 1.00 & 1 & 0 & 0 & 1 & 0 & $\mathrm{~ns}$ \\
\hline 107D & $22 / 01 / 02$ & 0.1739 & 1 & 0 & 1.00 & 1 & 0 & 0 & 1 & 0 & ns \\
\hline $107 \mathrm{E}$ & $22 / 01 / 02$ & 0.0948 & 5 & 0 & 0.57 & 4 & 0 & 0 & 2 & 1 & ns \\
\hline $110 \mathrm{C}$ & $19 / 02 / 02$ & 0.2906 & 4 & 4 & 1.00 & 2 & 0 & 0 & 2 & 0 & ns \\
\hline 120 & $19 / 02 / 02$ & 0.6958 & 61 & 0 & 0.69 & 61 & 0 & 0 & 14 & 3 & ns \\
\hline 202 & $13 / 02 / 02$ & 0.2385 & 3 & 0 & 0.60 & 3 & 0 & 0 & 2 & 1 & ns \\
\hline 213 & $19 / 02 / 02$ & 0.2531 & 4 & 1 & 1.00 & 3 & 0 & 0 & 3 & 0 & $\mathrm{~s}$ \\
\hline 303 & $12 / 02 / 02$ & 0.6135 & 39 & 0 & 0.74 & 37 & 2 & 1 & 15 & 2 & $\mathrm{~ns}$ \\
\hline \multicolumn{12}{|l|}{$4 \times 4$} \\
\hline $107 \mathrm{C}$ & $22 / 01 / 02$ & 0.2235 & 0 & 0 & 0 & 0 & 0 & 0 & 0 & 0 & ns \\
\hline 107D & $22 / 01 / 02$ & 0.1739 & 0 & 0 & 0 & 0 & 0 & 0 & 0 & 0 & ns \\
\hline $107 \mathrm{E}$ & $22 / 01 / 02$ & 0.0948 & 1 & 1 & 1.00 & 1 & 0 & 0 & 1 & 0 & ns \\
\hline $110 \mathrm{C}$ & $19 / 02 / 02$ & 0.2906 & 1 & 1 & 1.00 & 1 & 0 & 0 & 1 & 0 & ns \\
\hline 120 & $19 / 02 / 02$ & 0.6958 & 20 & 0 & 0.87 & 20 & 0 & 0 & 7 & 2 & $\mathrm{~s}$ \\
\hline 202 & $13 / 02 / 02$ & 0.2385 & 2 & 0 & 0.67 & 2 & 0 & 0 & 1 & 1 & ns \\
\hline 213 & $19 / 02 / 02$ & 0.2531 & 0 & 0 & 0 & 0 & 0 & 0 & 0 & 0 & ns \\
\hline 303 & $12 / 02 / 02$ & 0.6135 & 17 & 0 & 0.65 & 17 & 0 & 0 & 8 & 2 & $\mathrm{~s}$ \\
\hline
\end{tabular}

a Disease incidence $=$ number of CSD-symptomatic trees $/$ total number of trees in each plot.

b Number of $[x, y]$ lags significantly greater (SL+) or less (SL-) than expected by chance at $\alpha=0.05$.

${ }^{c}$ Strength of aggregation $=$ number of SL+ in core cluster $/$ total number of SL+.

${ }^{\mathrm{d}}$ Core size $=$ the number of significant SL+ lags contiguous with the [0.0] lag position that form a discrete group.

e Reflected cluster size $=$ the number of contiguous SL + in various clusters not contiguous with the core cluster.

$\mathrm{f}$ Total number of clusters $=$ the number of contiguous clusters of SL+ in the proximity pattern.

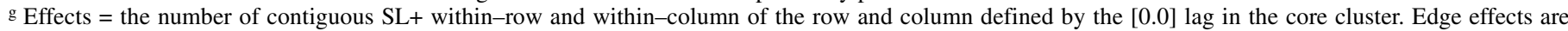
significant (s) or nonsignificant (ns) if (the number of SL+ at the distal edges of the proximity pattern / total number of SL+) is $\geq 5$ and $<5 \%$, respectively. 
tions, CSD symptoms are noticeable only in trees older than 22 months (N. Gimenes-Fernandes, unpublished data).

The cultivars of citrus differ in the level of expression of symptoms to CSD. Preliminary information from commercial orchards indicates a higher susceptibility for 'Valencia' compared with 'Pera' (N. Gimenes-Fernandes, unpublished data). The disease rates calculated between 2001 and 2002, using the Gompertz model (plots 102A, 107C, 107D, and 107E for 'Pera' and plot 303 for 'Valencia'), support this observation.

It is worthwhile to compare the epidemiological behavior of CSD and CTV. Citrus tristeza is a complex pathosystem. Isolates of CTV vary greatly in symptom expression, and a multitude of interactions can occur due to various combinations of the virus, host (scion/rootstock), aphid vector species, and environment. One of the most destructive diseases of citrus, CTV decline is
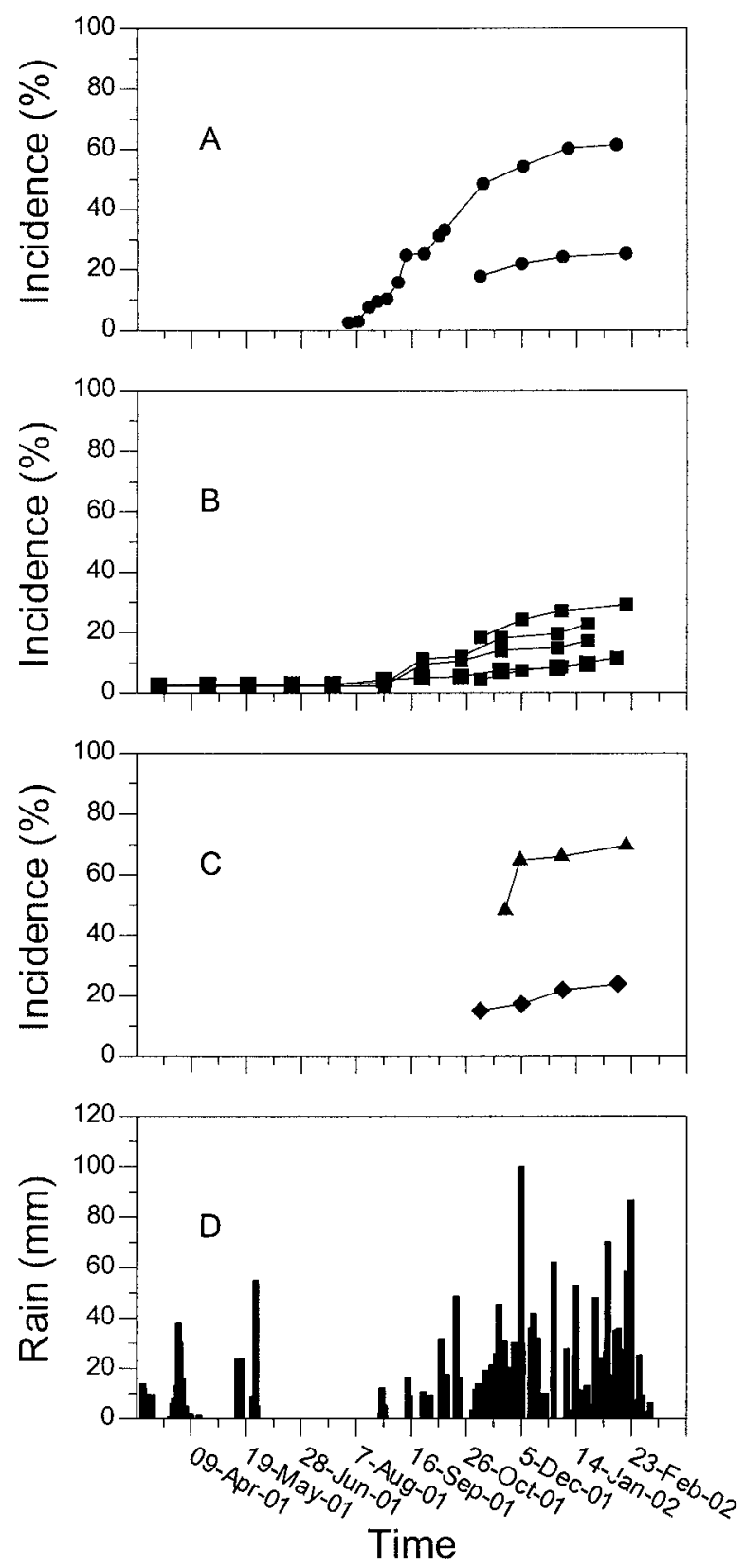

Fig. 5. Temporal increase of citrus sudden death, assessed as incidence of symptomatic trees over time, for different sweet oranges grafted on Rangpur lime. A, 'Valencia', plots 303 (top) and 213; B, 'Pera', plots (from top to bottom) 110C, 107C, 107D, 102A, and 107E; and C, 'Westin', plot 120 (top) and 'Natal'; and $\mathbf{D}$, daily amount of rain in millimeters. caused by certain CTV isolates that elicit a graft union incompatibility when infected sweet orange scions are grafted onto sour orange rootstocks $(2,37)$. In Brazil, citrus tristeza was first detected in 1937 and destroyed all of the trees grafted on sour orange rootstocks (around 9 million) in the following years. The problem was solved by substituting sour orange by Rangpur lime as rootstock. More than $85 \%$ of the 180 million citrus trees in Brazil today are grafted on Rangpur rootstock. Since 1937, the main CTV vector in Brazil has been the brown citrus aphid, Toxoptera citricida, but numerous other aphid species exist as well $(10,38)$.

Spatial analyses of CTV epidemics have been conducted previously in several countries, but mostly in absence of $T$. citricida. In these studies, Aphis gossypii was believed to be the major vector $(1,7,8,11,13,18,21,24,28,33)$. More recently, with the dissemination of $T$. citricida to other regions, epidemiological studies have been conducted in the presence of this vector $(19,21,25)$. For epidemics in the presence of $T$. citricida, the hypothesis that CTV spatial arrangement is random was rejected, at least for the spatial scales studied. The binomial index of dispersion, $D$, for various quadrat sizes suggested aggregations of CTV-positive trees for all plots within the quadrat sizes tested (including 2 by 2 and 4 by 4 ). Spatial autocorrelation analysis of proximity patterns suggested that aggregation often existed among quadrats of various sizes up to four lag distances, but significant lag positions discontinuous from the main proximity patterns were rare. Some asymmetry was also detected for some spatial autocorrelation proximity patterns. Gottwald et al. (19) interpreted these results to mean that, although CTV-positive trees did not often influence immediately adjacent trees, virus transmission was common within a local area of influence that extended two to eight trees in all directions. A pattern indicating aggregation of CTV-infected trees was also apparent from the Taylor binary law applied to these data (25).

Comparison of spatial patterns of CTV-infected trees in the presence of $T$. citricida and CSD-symptomatic trees reveals remarkable similarities $(19,21,25)$. The beta-binomial index of dispersion, $D$, for both diseases indicated a spatial structure of CSD-symptomatic and CTV-infected trees significantly nonrandom. For quadrat size 2 by 2 , the mean values of $D$ were 1.23 for CSD (98 data sets), 1.27 for CTV in the Dominican Republic (28 data sets), and 1.19 for CTV in Costa Rica (26 data sets). For quadrat size 4 by 4 , mean values of $D$ were 1.69 for CSD, 1.99 for CTV in the Dominican Republic, and 1.55 for CTV in Costa Rica [Gottwald et al. (19) for the Dominican Republic and Costa Rica data]. Similarly, for quadrat size 2 by 2 , the Taylor law for binary data produced almost identical results for CSD and CTV: $b=1.07$ and $A=0.22$ for CSD (98 data sets) and $b=1.07$ and $A=0.23$ for CTV (15 data sets) (25).

Also, for spatial lag correlation analyses the results for CSD and CTV (19) are remarkably similar: (i) core clusters for quadrat sizes 2 by 2 and 4 by 4 were identified for most plots in both diseases; (ii) core clusters were complete (i.e., saturated with significant positive lags) in the majority of cases for both diseases; (iii) the area of influence of like-CTV status had a radius of four to eight tree spacings compared with two to six tree spacings for CSD; and (iv) reflected clusters were very rare for all proximity patterns tested and transient with respect to time for both diseases.

Conversely, differences in spatial pattern between sudden death and tristeza diseases were found at the first spatial scale, i.e., among immediately adjacent trees within and across rows. For tristeza in Costa Rica and the Dominican Republic, Gottwald et al. (19), using ordinary runs analysis, failed to show a spatial relationship of virus status among immediately adjacent trees within or across rows. For CSD, we detected by ordinary runs analysis a consistent pattern of aggregation within rows. This pattern was also confirmed in our spatial autocorrelation analysis. This discrepancy is most likely related to the age of the plots analyzed and 
probably does not reflect any real difference between both pathosystems. While in the tristeza plots of Costa Rica and the Dominican Republic, plantings ranged from 1 to 5 years old (19), in our CSD plots $73 \%$ of plantings were older than 10 years. The effect of plant age on the aggregation of CTV-infected trees was already reported in the literature (20). In Israel and Florida, with A. gossypii as the main vector, aggregation of infected trees was only detected from the time that tree canopies grew together within the row, probably due to the movement of virus-carrying aphids that crawl along the continuous canopy of citrus branches. This is unlikely to have occurred in Costa Rica and the Dominican Republic plots because plants were too young and did not have interlocking canopies, but was evident in our plots.

The Gompertz annual disease progress rates reported in this paper for CSD (mean of 0.85 for $\mathrm{cv}$. Pera and 2.02 for $\mathrm{cv}$. Valencia), despite being preliminary, are compatible with calculated rates for CTV published in the literature with T. citricida as the main vector: a rate of 0.64 was reported for Brazil (3) and rates from 1.1 to 1.5 were reported for Costa Rica and the Dominican Republic (19). However, it must be noted that disease assessments for CSD were made visually, whereas for CTV in the indicated studies, disease incidence was determined serologically.

In plant pathology, the use of epidemiological analyses to generate hypotheses concerning the etiology of new diseases, with few exceptions $(4,29,39,43)$, have seldom been used. In this paper, we, like Sonoda et al. (39), consider that the knowledge of the spatial and temporal patterns of diseased plants is a useful starting point in studying the etiology of plant diseases. We also agree with Waggoner and Aylor (41) when they say that "epidemiologists are detectives," detectives of patterns.

Search for a causal agent in CSD-symptomatic trees including fungi (N. Gimenes-Fernandes and E. Feichtenberger, unpublished data), endogenous bacteria and phytoplasmas (M. Garnier, I. P. Bedendo, and M. A. Machado, unpublished data), and viroids (N. Duran-Vila, unpublished data) produced negative results. Only CTV was seen by electron microscopy (E. W. Kitajima, unpublished data) and detected by serological methods (J. A. M. Rezende, M. A. Machado, and M. Cambra, unpublished data) and by double-stranded RNA patterns (P. Moreno, unpublished data) in all samples examined, from both symptomatic and asymptomatic trees. CTV is prevalent in all citrus areas in Brazil and present in virtually all trees; about 80 million Pera/Rangpur lime trees are preimmunized with a mild strain of CTV in Brazilian orchards to cross-protect them from more severe CTV isolates (38). Based on these facts on the symptoms of the disease, combined with the spatial and temporal patterns described in this paper, one hypothesis is that CSD may be caused by an insectvectored pathogen, such as an undescribed new strain of CTV. Unfortunately, if a new strain of CTV has invaded the Brazilian citrus industry, it would be undetectable at this time due to our inability to discriminate it from known Brazilian CTV isolates with current serological assays and molecular probes. The hypothesis is thus untestable but still fits well in the concept currently gaining popularity that CTV may actually be a group of related viruses rather than a single entity (12). Although the hypothesis of a new vectored pathogen, such as a virus, can explain most known characteristics of CSD to date, it is important to remember that the purpose of a hypothesis is only to guide experiments to confirm or reject it. The similarities of spatial patterns of CSD and CTV is striking and should not be ignored, because their analyses and inferences give clues to the underlying spatial processes and thus possible etiology and causation of CSD. However, they are not conclusive in the absence of an identified pathogen.

\section{ACKNOWLEDGMENTS}

We thank A. J. Ayres of Fundecitrus, Araraquara, Brazil, for scientific support.

\section{LITERATURE CITED}

1. Bar-Joseph, M., and Loebenstein, G. 1973. Effects of strain source plant, and temperature on transmissibility of citrus tristeza virus by the melon aphid. Phytopathology 63:716-720.

2. Bar-Joseph, M., Marcus, R., and Lee, R. F. 1989. The continuous challenge of citrus tristeza virus control. Annu. Rev. Phytopathol. 27:292-316.

3. Bennett, C. W., and Costa, A. S. 1949. Tristeza disease of citrus. J. Agric. Res. 78:207-237.

4. Bergamin Filho, A., Amorim, L., Laranjeira, F. F., Berger, R. D., and Hau, B. 1998. Análise temporal do amarelecimento fatal do dendezeiro como ferramenta para elucidar sua etiologia. Fitopatol. Bras. 23:391396.

5. Campbell, C. L. 1998. Disease progress in time: Modelling and data analysis. Pages 181-206 in: The Epidemiology of Plant Diseases. D. G. Jones, ed. Kluwer Academic Publishers, Dordrecht, the Netherlands.

6. Campbell, C. L., and Madden, L. V. 1990. Introduction to Plant Disease Epidemiology. John Wiley \& Sons, New York.

7. Chellemi, D. O., Rohrbach, K. G., Yost, R. S., and Sonoda, R. M. 1988. Analysis of the spatial pattern of plant pathogens and diseased plants using geostatistics. Phytopathology 78:221-226.

8. Chellemi, D. O., Sonoda, R. M., Pelosi, R. R., and Cohen, M. 1991. Temporal and spatial comparisons between epidemics of citrus blight and citrus tristeza virus. Pages 289-296 in: Proc. Conf. Int. Organ. Citrus Virol., 11th. IOCV, Riverside, CA.

9. Collett, D. 1991. Modelling Binary Data. Chapman \& Hall, London.

10. Feichtenberger, E., Müller, G. W., and Guirado, N. 1997. Doenças dos citros (Citrus spp.). Pages 261-296 in: Manual de Fitopatologia: Doenças das Plantas Cultivadas. H. Kimati, L. Amorim, A. Bergamin Filho, L. E. A. Camargo, and J. A. M. Resende, eds. Ceres, São Paulo.

11. Fishman, S., Marcus, R., Talpaz, H., Bar-Joseph, M., Oren, Y., Salomon, R., and Zohar, M. 1983. Epidemiological and economic models for spread and control of citrus tristeza virus disease. Phytoparasitica 11:39-49.

12. Garnsey, S. M., Gottwald, T. R., and Yokomi, R. K. 1998. Control strategies for citrus tristeza virus. Pages 639-658 in: Plant Virus Disease Control. A. Hadidi, R. K. Khetarpal, and H. Koganezawa, eds. The American Phytopathological Society, St. Paul, MN.

13. Gibson, G. J. 1997. Investigating mechanisms of spatiotemporal epidemic spread using stochastic models. Phytopathology 87:139-146.

14. Gilligan, C. A. 1982. Statistical analysis of the spatial pattern of Botrytis fabae on Vicia faba: A methodological study. Trans. Br. Mycol. Soc. 79:193-200.

15. Gilligan, C. A. 1990. Comparison of disease progress curves. New Phytol. 115:223-242.

16. Gimenes-Fernandes, N., and Bassanezi, R. B. 2001. Doença de causa desconhecida afeta pomares cítricos no norte de São Paulo e sul do Triângulo Mineiro. Summa Phytopathol. 27:93.

17. Gottwald, T. R., Aubert, B., and Zhao, X.-Y. 1989. Preliminary analysis of citrus greening (Huanglungbin) epidemics in the People's Republic of China and French Reunion Island. Phytopathology 79:687-693.

18. Gottwald, T. R., Cambra, M., Moreno, P., Camarasa, E., and Piquer, J. 1996. Spatial and temporal analyses of citrus tristeza virus in eastern Spain. Phytopathology 86:45-55.

19. Gottwald, T. R., Garnsey, S. M., and Borbón, J. 1998. Increase and patterns of spread of citrus tristeza virus infections in Costa Rica and the Dominican Republic in the presence of the brown citrus aphid, Toxoptera citricida. Phytopathology 88:621-636.

20. Gottwald, T. R., Garnsey, S. M., Cambra, M., Moreno, P., Irey, M., and Borbón, J. 1997. Comparative effects of aphid vector species on increase and spread of citrus tristeza virus. Fruits 52:397-404.

21. Gottwald, T. R., Gibson, G. J., Garnsey, S. M., and Irey, M. 1999. Examination of the effect of aphid vector population composition on the spatial dynamics of citrus tristeza virus spread by stochastic modeling. Phytopathology 89:603-608.

22. Gottwald, T. R., Reynolds, K. M., Campbell, C. L., and Timmer, L. W. 1992. Spatial and spatiotemporal autocorrelation analysis of citrus canker epidemics in citrus nurseries and groves in Argentina. Phytopathology 82:843-851.

23. Gottwald, T. R., Richie, S. M., and Campbell, C. L. 1992. LCOR2spatial correlation analysis software for the personal computer. Plant Dis. 76:213-215.

24. Hughes, G., and Gottwald, T. R. 1998. Survey methods for assessment of citrus tristeza virus incidence. Phytopathology 88:715-723.

25. Hughes, G., and Gottwald, T. R. 1999. Survey methods for assessment of citrus tristeza virus incidence when Toxoptera citricida is the predominant vector. Phytopathology 89:487-494.

26. Hughes, G., and Madden, L. V. 1992. Aggregation and incidence of disease. Plant Pathol. 41:657-660

27. Hughes, G., and Madden, L. V. 1993. Using the beta-binomial distribu- 
tion to describe aggregated patterns of disease incidence. Phytopathology 83:759-763.

28. Hughes, G., McRoberts, N., Madden, L. V., and Gottwald, T. R. 1997. Relationships between disease incidence at two levels in a spatial hierarchy. Phytopathology 87:542-550.

29. Laranjeira, F. F., Amorim, L., Bergamin Filho, A., Berger, R. D., and Hau, B. 1998. Análise espacial do amarelecimento fatal do dendezeiro como ferramenta para elucidar sua etiologia. Fitopatol. Bras. 23:397403.

30. Madden, L. V., and Hughes, G. 1995. Plant disease incidence: Distributions, heterogeneity, and temporal analysis. Annu. Rev. Phytopathol. 33:529-564.

31. Madden, L. V., Louie, R., Abt, J. J., and Knoke, J. K. 1982. Evaluation of tests for randomness of infected plants. Phytopathology 72:195-198.

32. Madden, L. V., Nault, L. R., Murral, D. J., and Apelt, M. R. 1995. Spatial pattern analysis of the incidence of aster yellows disease in lettuce. Res. Popul. Ecol. 37:279-289.

33. Marcus, R., Fishman, S., Talpaz, H., Salomon, R., and Bar-Joseph, M. 1984. On the spatial distribution of citrus tristeza virus disease. Phytoparasitica 12:45-52.

34. Oliver, M. A. 1996. Geostatistics, rare disease and the environment. Pages 67-85 in: Spatial Analytical Perspectives on GIS. M. Fischer, H. J. Scholten, and D. Unwin, eds. Taylor \& Francis, London.

35. Pruvost, O., Boher, B., Brocherieux, C., Nicole, M., and Chiroleu, F. 2002. Survival of Xanthomonas axonopodis pv. citri in leaf lesions under tropical environmental conditions and simulated splash dispersal of inoculum. Phytopathology 92:336-346.

36. Pruvost, O., Gottwald, T. R., and Brocherieux, C. 1999. The effect of irrigation practices on the spatio-temporal increase of Asiatic citrus canker in simulated nursery plots in Reunion Island. Eur. J. Plant Pathol. 105:23-37.

37. Rocha-Peña, M. A., Lee, R. F., Lastra, R., Niblett, C. L., Ochoa-Corona, F. M., Garnsey, S. M., and Yokomi, R. K. 1995. Citrus tristeza virus and its aphid vector Toxoptera citricida. Threats to citrus production in the Caribbean and Central and North America. Plant Dis. 79:437-445.

38. Rossetti, V. V. 2001. Manual Ilustrado de Doenças dos Citros. FEALQ, Piracicaba.

39. Sonoda, R. M., Chellemi, D. O., Pelosi, R. R., and Cohen, M. 1991. Patterns of citrus blight incidence in bedded Indian River area groves. Proc. Fla. State Hortic. Soc. 104:181-184.

40. Upton, G., and Fingleton, B. 1985. Spatial Data Analysis by Example. Vol. 1. Point Pattern and Quantitative Data. John Wiley \& Sons, Chichester.

41. Waggoner, P. E., and Aylor, D. E. 2000. Epidemiology: A science of patterns. Annu. Rev. Phytopathol. 38:71-94.

42. Xu, X.-M., and Ridout, M. S. 2000. Effects of quadrat size and shape, initial epidemic conditions, and spore dispersal gradient on spatial statistics of plant disease epidemics. Phytopathology 90:738-750.

43. Yokomi, R. K., Garnsey, S. M., Young, R. H., and Grimm, G. R. 1984. Spatial and temporal analysis of citrus blight incidence in Valencia orange groves in Central Florida. Pages 260-269 in: Proc. Conf. Int. Organ. Citrus Virol., 9th. IOCV, Riverside, CA. 